\title{
QUANDO A EXTENSÃO UNIVERSITÁRIA DEBATE TEMAS EMERGENTES: O CASO DO TURISMO ESPORTIVO
}

\author{
When university debates emerging topics: the case of sport tourism?
}

Cuando la extensión universitaria debate temas emergentes: el caso del turismo esportivo

\section{Carlos Henrique de Vasconcellos Ribeiro ${ }^{1}$}

\section{RESUMO}

O objetivo desta pesquisa é relatar a experiência extensionista em formato de evento acadêmico denominado "Turismo Esportivo: o Rio Pós Megaeventos". O Rio de Janeiro recebeu na última década diversos eventos esportivos, inclusive dois de nível planetário. Porém, a importância destes eventos ainda não foi suficientemente estudada e seus impactos econômicos e sociais precisam ser sentidos por todos. Assim, o Seminário Esporte e Turismo: o Rio Pós Megaeventos trouxe os principais agentes de atuação neste segmento que contribuem para o turismo esportivo nessa cidade. O evento foi de caráter científico, trazendo experiências bem-sucedidas, sendo aberto a todos que estudam, trabalham ou querem compreender melhor esta área de atuação e conhecimento.

Palavras-chave: Turismo Esportivo; Evento acadêmico; Extensão Universitária.

\footnotetext{
1 Doutor em Educação Física, Universidade Santa Úrsula.
} 


\section{ABSTRACT}

The aim of this research is to report the extensionist experience in academic event format called "Sports Tourism: The Rio Post Mega events". Rio de Janeiro has hosted several sporting events in the last decade, including two planetary-level events. However, the importance of these events has not yet been sufficiently studied and their economic and social impacts need to be felt by all. Thus, the Sports and Tourism Seminar: Rio Pós Megaeventos brought the main agents of activity in this segment that contribute to sports tourism in this city. The event was of a scientific nature, bringing successful experiences, being open to all who study, work or want to better understand this area of activity and knowledge.

Keywords: Sports Tourism; Academic event; University Event.

\section{RESUMEN}

El objetivo de esta investigación es reportar la experiencia extensionista en el formato de un evento académico denominado \&quot;Turismo Esportivo: o Rio Pós Megaeventos\&quot;. En la última década, Río de Janeiro ha sido sede de varios eventos deportivos, incluyendo dos de nivel planetario. Sin embargo, la importancia de estos acontecimientos aún no ha sido suficientemente estudiada y sus impactos económicos y sociales deben ser sentidos por todos. Así, el "Seminario Deporte y Turismo: Río Post Mega eventos" trajo a los principales agentes de acción en este segmento que contribuyen al turismo deportivo en esta ciudad. El evento fue de carácter científico, aportando experiencias exitosas, estando abierto a todos los que estudien, trabajen o quieran comprender mejor esta área de actividad y conocimiento.

Palabras clave: Turismo Esportivo; Evento Académico; Extensión Universitaria. 


\section{INTRODUÇÃO}

A extensão universitária é um dos pilares da educação superior no Brasil, em conjunto com o ensino e a pesquisa (GONÇALVES, 2015; GANDOLFI, 2018). O desenvolvimento de atividades extensionistas precisa estar em consonância com o papel social da universidade no que condiz à promoção de ações, encontros e reuniões com representantes da sociedade civil, órgão do governo em suas diferentes esferas de atuação e, claro, comunidade acadêmica (ANDRADE et al., 2020).

Documentos oficiais embasam legalmente as ações extensionistas no âmbito das universidades brasileiras (BRASIL, 2020; 2018). Há uma preocupação para que o conhecimento que vem sendo produzido alheio à participação dessas possa ser sistematizado, fazendo com que uma cadeia de profissionais seja beneficiada, trazendo, assim, desenvolvimento econômico através da inovação (ETZKOWITZ, 2017).

Dessa forma, temáticas pertinentes a esse conhecimento precisam ter, no espaço universitário, um espaço privilegiado de discussão, sobretudo quando é possível avaliar as perspectivas de formação humana que ofereçam perspectivas de geração de emprego e renda dentro de uma cadeia produtiva de prestação de serviços (ARANTES, DESLANDES, 2017).

Especificamente referente ao tema abordado neste artigo, tem-se, como exemplo, a prática de esportes ao ar livre na cidade do Rio de Janeiro, que tem no clima, na Geografia e na cultura de seus moradores fontes de incentivo. Assim, praticar atividade física em áreas livres, próximo à natureza, está incorporado ao cotidiano, fazendo parte da cultura e do estilo de vida do carioca.

Os que moram na cidade e os que a visitam podem realizar trilhas pela Floresta da Tijuca, aprender stand up paddle, voar de asa delta em São Conrado. Para os menos ativos fisicamente, uma ida ao Maracanã ou ao Museu da CBF pode ser uma boa opção de torcida e cultura. Depois da passagem dos megaeventos esportivos, como a Copa do Mundo FIFA, em 2014, e das Olímpiadas, em 2016, inúmeras intervenções foram realizadas, e espaços como a Orla Conde e a extensão do Metrô até a Barra da Tijuca se transformaram em novos equipamentos de visitação e facilidade de mobilidade urbana.

Porém, a combinação entre cultura esportiva e megaeventos esportivos ainda não foi bem compreendida pelo setor de turismo, sobretudo em relação a estudos e pesquisas que procurem avaliar os impactos dos que visitam a cidade para praticar esportes - tais como provas de corrida de rua -, ou como torcedores que visitam os equipamentos deixados pela passagem destes megaeventos na cidade (OLIVER, 2012). 
Sendo assim, o objetivo desta pesquisa é relatar a experiência extensionista em formato de evento acadêmico denominado "Turismo Esportivo: o Rio Pós Megaeventos”.

Tal objetivo justifica-se devido à escassez de exemplos teóricos e empíricos que demonstrem os potenciais de desenvolvimento econômico e social desta segmentação turística. Em linhas gerais, é como se os setores esportivos e turísticos não dialogassem e as iniciativas - quando acontecem - advêm mais de um voluntarismo e necessidade de realização dos eventos esportivos e menos de uma política pública voltada para o setor. O poder público, a iniciativa privada e a sociedade podem encontrar soluções juntos. Eventos acadêmicos como esse oferecem essa oportunidade.

\section{METODOLOGIA}

Essa pesquisa é de natureza qualitativa, exploratória e descritiva (GIL, 2008). Os dados coletados foram realizados durante a ação extensionista denominada "Turismo Esportivo: o Rio Pós Megaeventos".

O evento ocorreu no dia 05 de dezembro de 2019 na Universidade Santa Úrsula, Rio de Janeiro. Como evento acadêmico, foi realizada uma inscrição prévia, de forma gratuita, ao público interessado, na qual obteve-se 44 inscritos ouvintes. Realizada a inscrição, cada participante ao final do evento recebia um certificado de participação.

O evento foi uma iniciativa da Coordenação de Extensão, que convidou entidades privadas e públicas envolvidas no setor turístico e esportivo da cidade e do estado do Rio de Janeiro.

Abaixo, o cronograma para a realização do evento:

\section{Quadro 1 - Cronograma de ação do Projeto de Extensão}

\begin{tabular}{|c|c|c|}
\hline Etapa & Ação & Duração \\
\hline $1^{0}$ & Convite às instituições & 30 dias \\
\hline $2^{0}$ & Abertura de inscrições ao público & 20 dias \\
\hline $3^{0}$ & $\begin{array}{l}\text { Recebimento de trabalhos de } \\
\text { pesquisa/relatos de experiência }\end{array}$ & 15 dias \\
\hline
\end{tabular}

Fonte: Produção dos autores, 2021. 
As entidades foram convidadas por meio da seguinte redação, através de e-mail:

"A Universidade Santa Úrsula irá realizar o Seminário "Esporte e Turismo: o Rio Pós Megaeventos. O objetivo desse evento acadêmico é discutir os cenários para desenvolvimento dos eventos esportivos de potencial turístico no Rio de Janeiro, e apontar as questões que envolvem inovação, emprego e renda na cidade para os próximos anos neste setor. Gostaríamos de convidar sua instituição para participar na forma de Palestrante, em uma mesa-redonda que contará com outros participantes de mesma importância e visibilidade. Vocês podem desenvolver uma palestra sobre as ações do SESC neste segmento, e os projetos que estão sendo desenvolvidos por vocês.

Data: 05 de dezembro, às 10:00h ou às 18:00h, Salão Azul. Palestra com duração de 20 minutos. A Universidade Santa Úrsula fica na Rua Fernando Ferrari, n:75, Botafogo, perto da estação do Metrô Flamengo”.

Foram as seguintes as entidades que aceitaram o convite de participação: Tembici, Spiridon, Secretaria de Estado de Turismo do Estado do Rio de Janeiro, HotéisRio e FEMERJ.

Abaixo, o material de divulgação sobre o evento acadêmico:

Figura 1 - Arte de divulgação do Evento

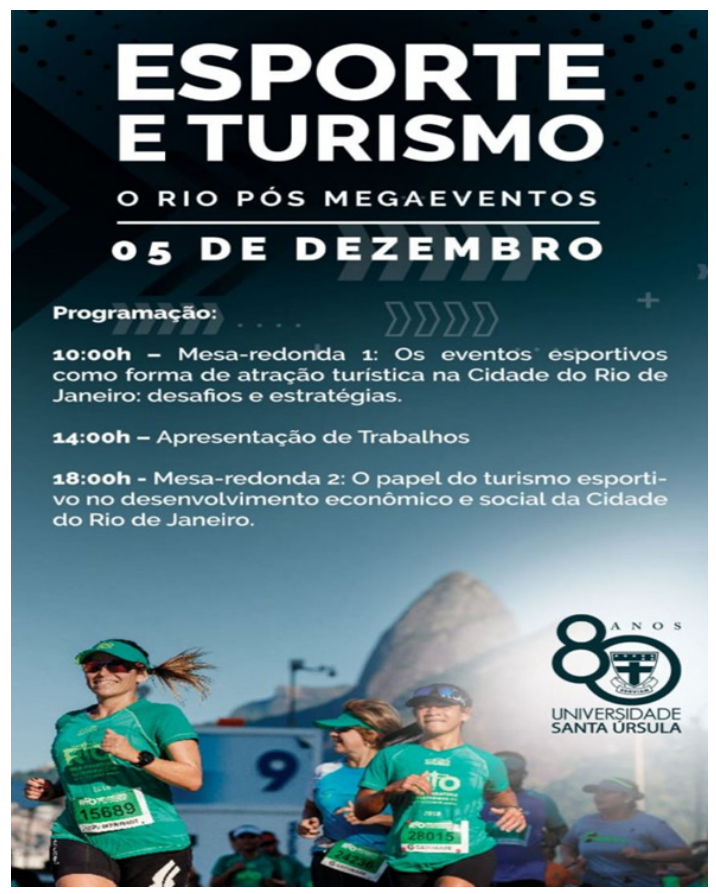

Fonte: Arquivo dos autores, 2021. 


\section{RESULTADOS E DISCUSSÃO}

Foram contabilizadas 54 inscrições, ao todo, para o evento. Desses, 43 compareceram, conforme lista de presença disponibilizada para a retirada do certificado. Em relação aos participantes, 31 advinham de instituições de ensino superior, conforme dados fornecidos durante o preenchimento do formulário. Os demais pertenciam a empresas ligadas ao setor de turismo, ligadas direta ou indiretamente aos assuntos pertinentes ao turismo esportivo.

A empresa Tembici é uma empresa de compartilhamento de bicicletas na cidade do Rio de Janeiro. Nessa cidade, ela tem como patrocinadora de suas bicicletas o banco Itaú, que faz com que dezenas de estações de compartilhamento estejam presentes em diversos pontos turísticos, tais como praia de Copacabana, Pão de Açúcar e Orla Conde.

Já a empresa Spiridon é especializada em eventos esportivos de corrida de rua. Maratona Rio, por exemplo, é seu produto mais conhecido. O evento agrega mais de 30 mil pessoas em dois dias de eventos de corridas de rua espalhadas pelas zonas oeste e sul da cidade do Rio de Janeiro.

A Secretaria Estadual de Esporte do Rio de Janeiro é um ente do poder público interessado em fomentar um ambiente de negócios que possibilite que a iniciativa privada seja amparada. Assim, um calendário de eventos esportivos que seja viável ao longo do ano é uma das metas dessa secretaria.

A HotéisRio é uma associação do grupo do mercado hoteleiro da cidade do Rio de Janeiro. Como entidade de classe, representa o setor, vocalizando as necessidades dos empresários e viabilizando, junto ao poder público, iniciativas para que o setor cresça e oportunize empregos, elevando a melhoria dos serviços prestados.

A FEMERJ, Federação de Esportes de Montanha da Cidade do Rio de Janeiro é uma entidade sem fins lucrativos, que representa os praticantes dessa atividade esportiva através de clubes de montanha e de uma associação de profissionais de escalada.

Além do público e das empresas, o evento abriu oportunidades de apresentação de trabalhos para interessados em mostrar suas pesquisas e/ou relatos de experiência relacionados ao tema do evento. Dois trabalhos foram apresentados: o primeiro versava sobre os eventos do futebol feminino na cidade e o segundo abordava os impactos dos megaeventos esportivos para a classe de professores de educação física.

São necessárias parcerias, estudos e pesquisas dos diferentes entes, tanto com fins de alavancar o crescimento do setor quanto de avaliar os impactos - de emprego e geração de renda - que estes eventos deixam para a cidade e o estado do Rio de Janeiro. 
Os estudos sobre turismo e esporte têm forte vinculação com o setor de eventos, podendo ser classificados como: cívico, político, educativo, cultural, científico, artístico, desportivo e religioso e turístico (ZANELLA, 2006). Dentre as vantagens dos eventos esportivos, destaca-se que eles podem acontecer em diversas épocas do ano, e, havendo um planejamento de longo prazo em acordo com as instâncias governamentais e com a iniciativa privada, é possível adequá-los para períodos considerados de pouca atratividade turística.

Em cidades como o Rio de Janeiro, este período é compreendido pelos meses mais frios do ano, a partir de março. Para a compreensão destas perspectivas, Santos e Souza (2012) afirmam que

[...] Esse nicho turístico, o do segmento esportivo, tem ainda a vantagem de conseguir trazer para o país receptor um fluxo turístico em períodos de baixa temporada, atraindo não somente atletas, mas também expectadores e o pessoal envolvido no evento, exercendo, assim, importante papel de promoção da localidade enquanto destinação turística. Afinal de contas, esses turistas tendem também a desembolsar mais do que a média do turista convencional durante sua estadia na localidade visitada (SANTOS; SOUZA,2012, p. 2).

Dessa forma, percebe-se o grande potencial de captação de turistas que estão dispostos a visitar a cidade com vistas à prática de atividade física - tais como praticar corrida de rua, visitar os locais por onde passaram os megaeventos (como o Maracanã - localizado no bairro da Tijuca, área da região da zona norte da cidade - e o Parque Olímpico - localizado na Barra da Tijuca, zona oeste do município), ou ainda assistir a eventos esportivos, tais como a competição de tênis denominada Rio Open ou a final de uma competição de futebol em nível internacional, como a final da Copa Libertadores.

Segundo Ribeiro (2019), é necessário, em relação a este tipo de atividade física, a compreensão de que

Provas bem organizadas e que passam por locais icônicos, que tenham belezas naturais durante a competição, somam-se às experiências de antes e depois do evento, e claro que há impactos econômicos que precisam ser levados em conta. Tente visitar Nova York na primeira semana de 
novembro, por exemplo, e você sentirá no bolso o aumento do preço dos quartos dos hotéis, sobretudo daqueles localizados nas áreas por onde a maratona da cidade acontece. A mesma situação vale para Berlim, Londres, Tóquio e a recém-badalada Jerusalém, sem deixar de mencionar a maratona das maratonas, a da cidade de Boston (RIBEIRO, 2019, p. 37).

Há uma demanda de mercado de trabalho sobre essa associação entre turismo e esporte, e é dentro da universidade que debates como esse podem gerar material teórico sistematizado para colaborar com essa realidade: a extensão universitária é espaço privilegiado para promover eventos com essa característica, em que os entes envolvidos discutem a realidade do setor e ainda têm a possibilidade de dar visibilidade às suas iniciativas.

Para melhor compreensão desse fenômeno, são exemplos de turismo esportivo as seguintes ações:

Figura 2 - Associação entre uma empresa aérea e o calendário de corridas de rua

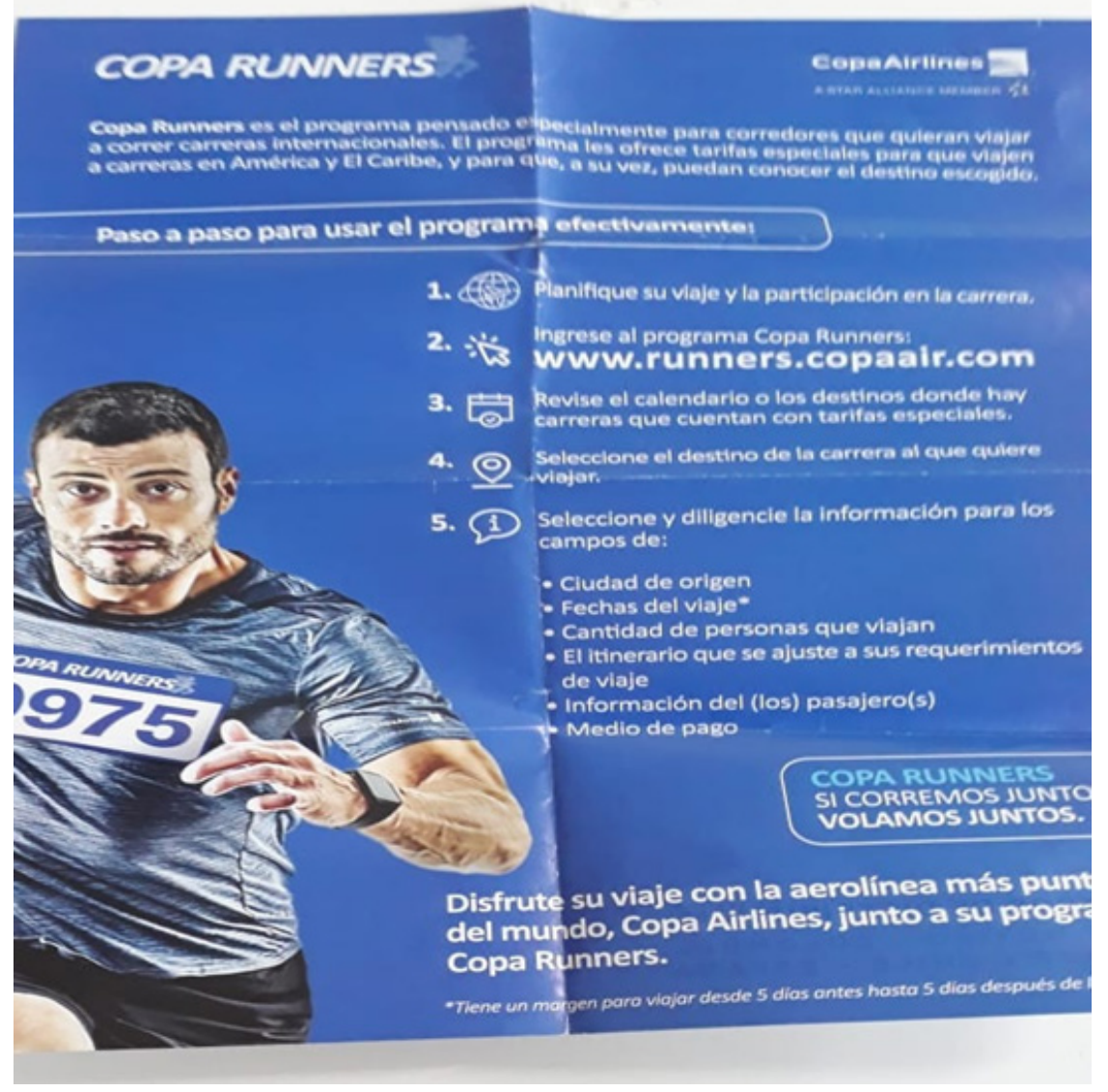

Fonte: Arquivo dos autores (2021). 
Figura 3 - Poder público municipal incentivando a prática esportiva

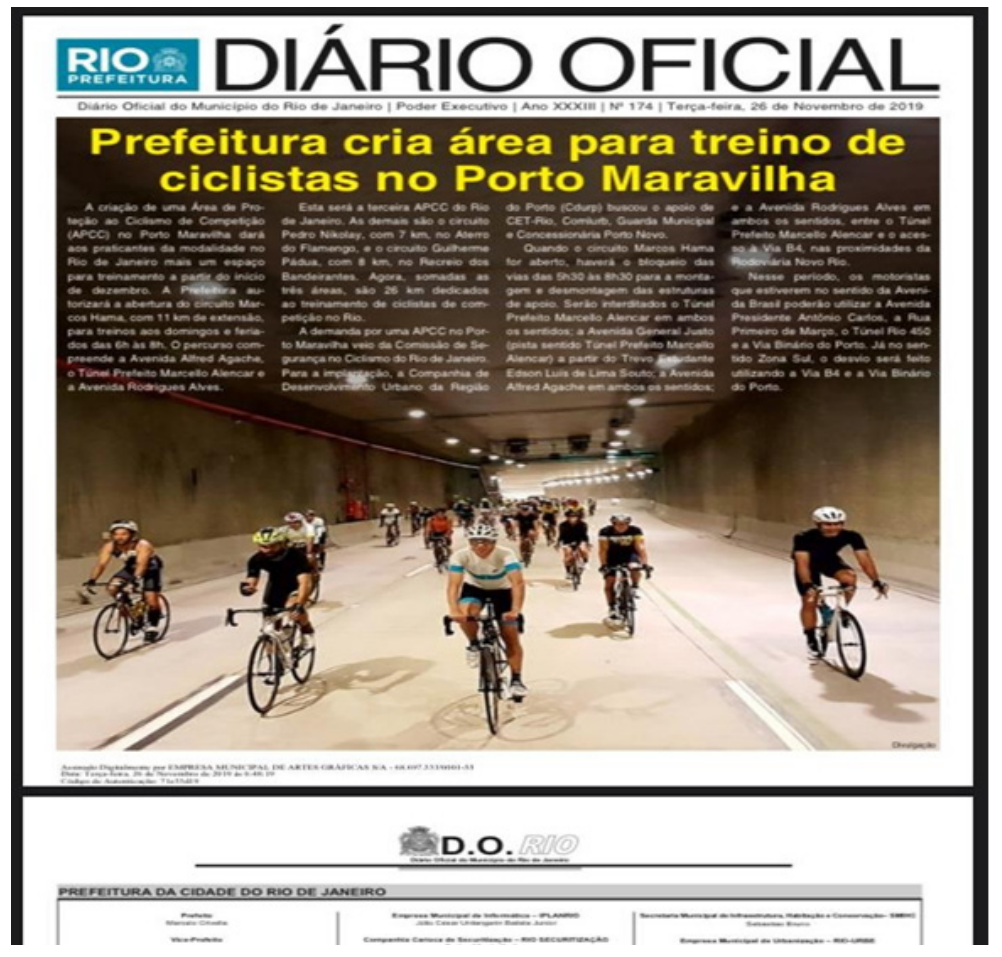

Fonte: Prefeitura do Rio de Janeiro (2021).

Figura 4 - Evento esportivo com apoio hoteleiro

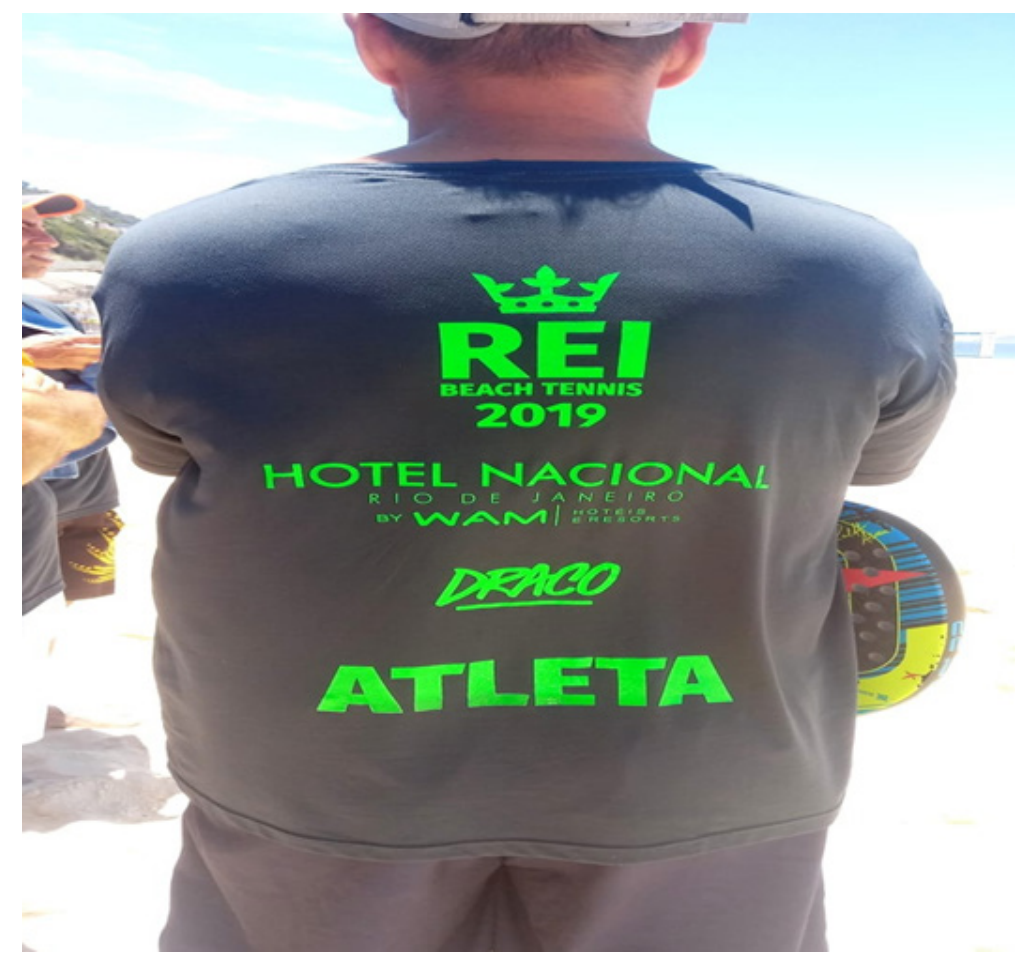

Fonte: Arquivo dos autores (2021). 
Neste sentido, o evento tema desta pesquisa teve a divulgação feita pela FAPERJ, através do seu semanário de divulgação de eventos das entidades de ensino e pesquisa do Estado (Figura 5):

Figura 5 - Divulgação do evento pela Agência de Pesquisa do Estado do Rio de Janeiro

\begin{abstract}
A experimentaçāo em humanos e as possibilidades e riscos para a análise histórica serão a pi Universidade de Michigan, Joel D. Howell. O professor é o próximo convidado do Encontro às 1 Saúde (CDHS) da Fundação de Oswaldo Cruz (Fiocruz), em Manguinhos. Aberta aos interessa simultânea. Em sua apresentaçāo, Howell discutirá o tema a partir de três casos históricos: as mortalidade nas maternidades em Viena em meados do século XIX; o trabalho de $\mathrm{J}$. Marion Si mulheres escravizadas no sul dos Estados Unidos no periodo pré-Guerra Civil; e a pesquisa de distúrbios mentais na Willowbrook State School, em Nova York, na década de 1950. Mais infor desafios-para-analise-historica
\end{abstract}

\title{
Centro de Artes da UFF realiza evento em homenagem a Nise da Silveira
}

o Centro de Artes da Universidade Federal Fluminense (UFF) se inspira no legado da médica p outubro a 9 de novembro. Com uma série de atividades culturais, o projeto marca os 20 anos c métodos de tratamento que revolucionaram a questão da saúde mental e a terapêutica ocupa' em massa. Dois eixos culturais ganham destaque na programação: as artes visuais, na semar http://www.uff.br/?q=events/nise-da-silveira-20-anos-apos-sua-morte-legado-da-psiquiatra-bre

Senac Rio realiza o $1^{*}$ Coloquio do Núcleo de Estudos Cidades Inteligentes

Os alunos do curso de Análise e Desenvolvimento de Sistemas do Senac Rio de Janeiro convis Colóquio Neci, será realizado na próxima quinta-feira, dia 31 de outubro, na Faculdade de Tecn evento, haverá a apresentaçăo do projeto Neci, palestra com os idealizadores da Plataforma A Inteligentes. As inscriçōes podem ser realizadas até o dia 30 de outubro, pelo link: https://doc: $\mathrm{d} 6 \mathrm{~g} / \mathrm{viewform}$ ?vc=0\&c=0\&w=1. Mais informaçōes: https://www.rj.senac.br/eventos

\section{Fiocruz lança Porto Livre, plataforma para livros em acesso aberto}

O Instituto de Comunicaçăo e Informaçăo em Saúde (Icict), da Fundaçāo Oswaldo Cruz (Fiocru livros em formato digital, oferecendo aos internautas acesso livre a centenas de títulos com t $\epsilon$ que já dispōe de mais de 400 títulos, seleciona, organiza e disponibiliza obras que colaboram । debatidas e lidas livremente, de forma gratuita. O novo portal reúne livros editados em open ac pesquisa, editoras, movimentos sociais e ONGs, por exemplo. Os primeiros títulos disponíveis Programa de Pós-Graduação em Informação e Comunicação em Saúde (PPGICS), do Icict. Ma submeter suas obras à plataforma, para que sejam avaliadas pelo Conselho Curador, que irá d em ambos os casos só serăo aprovados livros licenciados para livre circulaçăo na internet. Mi

\section{Universidade Santa Û́rsula realizará um seminário sobre megaeventos}

A Universidade Santa Úrsula (USU) vai realizar, no dia 5 de dezembro, o seminário "Esporte e T diversas áreas para discutir a importăncia e os impactos económicos e sociais desse tipo de . informaçōes: http://usu.br/noticia/coordenador-de-educacao-fisica-planeja-seminario-na-usu

Fonte: Fundação de Amparo à Pesquisa do Estado do Rio de Janeiro (2021).

Os debates realizados durante o evento se pautaram na seguinte questão norteadora: como sua entidade pode contribuir para melhorar o turismo esportivo no Rio de Janeiro?

Para as empresas, suas contribuições passam pelo aumento no número de eventos, assim elas podem planejar, contratar e oferecer condições de realizar suas iniciativas, tais como acontece no setor hoteleiro. Sobre esse setor específico, há uma discussão de como fomentar o turismo na cidade em períodos de baixa estação, normalmente compreendido entre março/junho e entre agosto/ outubro.

No contexto, as empresas também pediram ao poder público presente - da esfera do poder executivo estadual - que oferecessem uma legislação que não impedisse que esses eventos fossem homologados em períodos razoáveis entre o pedido para que ele aconteça - como no caso de uma corrida de rua - até que a vistoria e liberação do espaço aconteça. Eventos que conseguem a chan- 
cela do poder público muito próximo de sua liberação, afugentam, como explicado pelas empresas presentes, a possibilidade de atração de patrocinadores, visibilidade nas redes sociais e atração midiática.

Em relação à Secretaria de Estado de Esporte, houve o compromisso de diálogo com as entidades presentes. Da parte desse órgão, houve a sugestão de construção de uma pauta que ajuste com os demais órgãos públicos o atendimento às necessidades apresentadas pelas entidades privadas. A questão de um calendário esportivo para todo o ano, e não apenas no período de férias, por exemplo, foi uma sugestão dessa Secretaria.

\section{CONCLUSÕES}

Eventos como esse precisam ser registrados e catalogados. Uma das formas de conseguir que as ações extensionistas universitárias ganhem forma e visibilidade é a transformação dessas iniciativas em artigos acadêmicos e relatos de experiência - como se faz através desse documento -, para que as ações futuras permitam se utilizar do conhecimento sistematizado, preenchendo suas lacunas.

A universidade brasileira tem um papel social importante na colaboração do desenvolvimento econômico e social do país. Porém, é necessário que ela esteja atenta às oportunidades de reunir entidades do setor privado e público em eventos que tragam para discussão temas relacionados à formação e intervenção profissional que nem sempre são discutidos no ambiente acadêmico, mas que, de forma complementar, podem colaborar para a formação de mão de obra mais qualificada. Assim, turismo e esporte, fenômenos distintos, mas complementares, precisam dialogar e oferecer soluções que beneficiem não apenas o setor, mas que promovam o desenvolvimento social da cidade e estado onde estão inseridos.

\section{REFERÊNCIAS}

ANDRADE, João et al. Dia mais feliz! Relato de uma oficina de arteterapia em um Centro de Atenção Psicossocial. EntreAções: diálogos em extensão, Juazeiro do Norte, v. X, n. X, p. x-x, jan./jun. 2020.

ARANTES, Álisson.; DESLANDES, Maria. (2017). A extensão universitária como meio de transformação social e profissional. Sinapse Múltipla. v. 6, n. 2, p.179-183. 
BRASIL, Ministério da Educação. Conselho Nacional de Educação. Câmara de Educação Superior. Resolução CNE/CES 7/2018. Diário Oficial da União, Brasília, 19 de dezembro de 2018, Seção 1, pp. 49 e 50.

BRASIL, Presidência da República. Lei 10.097, de 19 de dezembro de 2000.

ETZKOWITZ, Henry. Triple helix: university-industry-government innovation and entrepreneurship. London: Routledge, 2017.

GANDOLFI, Peterson; BORGES, Ana; FERREIRA, Denilson; GANDOLFI, Maria. Quem transforma se transforma: extensionistas no exercício da extensão. Em Extensão, Uberlândia, v. 17, n. 2, p. 88-109, 2018.

GIL, Antônio. Métodos e técnicas de pesquisa social. São Paulo: Atlas, 2008.

GONÇALVES, Nadia. Indissociabilidade entre Ensino, Pesquisa e Extensão: um princípio necessário. Perspectiva, Florianópolis, v. 33, n. 3, p. 1229 - 1256, set./dez. 2015.

OLIVER, Iata. Megaeventos esportivos e relações internacionais como estratégia de atração turística. Observatório de Inovação do Turismo - Revista Acadêmica. Vol. VII, n. ${ }^{\circ}$, Rio de Janeiro, 2012 .

RIBEIRO, Carlos. Turismo esportivo e seu papel no desenvolvimento econômico e social. Turismo em Pauta, v. 1, p. 37, 2019.

SANTOS, Rodrigo; SOUZA, Norma. Eventos esportivos e Turismo: definição de mercado e perspectivas de atuação. Revista Científica Eletrônica de Turismo. Ano IX, Número 16, p. 2, 2012.

ZANELLA, Luis. Manual de organização de eventos: planejamento e operacionalização. São Paulo: Atlas, 2006. 